\title{
Lung transplantation for interstitial lung disease
}

\author{
Siddhartha G. Kapnadak ${ }^{1}$ and Ganesh Raghu ${ }^{1,2}$
}

${ }^{1}$ Division of Pulmonary, Critical Care and Sleep Medicine, Dept of Medicine, University of Washington, Seattle, WA, USA. ${ }^{2}$ Dept of Laboratory Medicine and Pathology, University of Washington, Seattle, WA, USA.

Corresponding author: Ganesh Raghu (graghu@uw.edu)

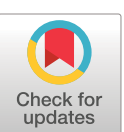

This version is distributed under the terms of the Creative Commons Attribution NonCommercial Licence 4.0. For commercial reproduction rights and permissions contact permissions@ersnet.org

Received: 18 Jan 2021 Accepted: 2 April 2021

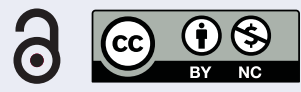

Shareable abstract (@ERSpublications)

This review summarises the many unique and important features in patients who undergo lung transplant for interstitial lung disease that can impact pre-transplant disease progression, transplant risks, candidacy and post-transplant management https://bit.ly/2PU1FLq

Cite this article as: Kapnadak SG, Raghu G. Lung transplantation for interstitial lung disease. Eur Respir Rev 2021; 30: 210017 [DOI: 10.1183/16000617.0017-2021].

\section{Abstract}

Lung transplantation (LTx) can be a life-extending treatment option for patients with advanced and/or progressive fibrotic interstitial lung disease (ILD), especially idiopathic pulmonary fibrosis (IPF), fibrotic hypersensitivity pneumonitis, sarcoidosis and connective tissue disease-associated ILD. IPF is now the most common indication for LTx worldwide. Several unique features in patients with ILD can impact optimal timing of referral or listing for LTx, pre- or post-transplant risks, candidacy and post-transplant management. As the epidemiology of LTx and community practices have evolved, recent literature describes outcomes and approaches in higher-risk candidates. In this review, we discuss the unique and important clinical findings, course, monitoring and management of patients with IPF and other progressive fibrotic ILDs during pre-LTx evaluation and up to the day of transplantation; the need for co-management with clinical experts in ILD and LTx is emphasised. Some post-LTx complications are unique in these patient cohorts, which require prompt detection and appropriate management by experts in multiple disciplines familiar with telomere biology disorders and infectious, haematological, oncological and cardiac complications to enhance the likelihood of improved outcomes and survival of LTx recipients with IPF and other ILDs.

\section{Introduction}

Lung transplantation (LTx) can extend and improve quality of life for patients with advanced lung disease. The International Society for Heart and Lung Transplantation (ISHLT) has reported a steady increase in worldwide transplants over the past two decades, with nearly 4500 performed in 2017 [1]. These data are estimated to capture approximately three-quarters of worldwide lung transplant activity, of which roughly $55 \%$ and $34 \%$ of total transplants have been performed in North America and Europe, respectively [2]. The distribution of diagnoses undergoing LTx has also evolved, with interstitial lung disease (ILD) surpassing COPD as the most common indication in 2007, and the percentage of total worldwide transplants for ILD having increased in 2017 to 40.5\%, including 32.4\% for idiopathic pulmonary fibrosis (IPF) [1]. The trend is most pronounced in North America, including the USA, where 60\% of total lung transplants were performed for restrictive lung disease in 2018 [1, 3]. With the community transitioning toward a philosophy of transplanting those at highest short-term risk of death, simulations evaluating broader organ sharing and high emergency allocation systems also project increasing transplant rates among candidates with ILD [4-6].

LTx outcomes have improved for patients transplanted for ILD and other diagnoses. The ISHLT reports a median post-transplant survival of 5.2 years for patients with idiopathic interstitial pneumonia, and 6.7 years for other ILDs transplanted between 1992 and 2017, with outcomes improving in the most recent years [1]. In IPF treatment guidelines by the American Thoracic Society (ATS)/European Respiratory Society (ERS)/Japanese Respiratory Society (JRS)/Latin American Thoracic Association (ALAT), LTx receives a strong recommendation based on a $75 \%$ reduced risk of death compared to medical management 
alone in well-selected patients, a survival benefit that probably also extends to patients with other severe or progressive ILDs [7-11].

With a growing population of pre- and post-transplant patients with ILD, there is increasing need to fully appreciate the unique issues faced by this complex population that can impact candidacy, peri-operative risks and post-LTx management. In this article, we review the unique and important considerations in patients transplanted for IPF and other fibrotic lung diseases.

Consideration and timing of LTx in patients with ILD

Preparing for LTx in a given patient includes the separate, often overlapping phases of 1) transplant referral; 2) an evaluation period guided by the transplant centre; 3) active listing by the transplant team; and 4) concurrent management of disease progression by an experienced ILD team (figure 1). Determining the optimal timing can be challenging, and particularly in IPF, some advocate for a philosophy of broad referral for LTx as early as feasible, while others, acknowledging limitations in resources including transplant programme capacity, suggest a more selective approach [12]. International guidelines recommend that LTx be considered in patients with chronic lung disease who have a high risk of death within 2 years [13, 14], and the timing of both referral and listing for LTx incorporate current quality of life and expected survival, along with patient preferences.

IPF, the prototype ILD manifesting progressive pulmonary fibrosis carries a generally poor prognosis with median survival 2-5 years from diagnosis [13, 15-17]. However, prediction in a given individual remains challenging, considering that $>20 \%$ of the overall IPF population exhibits a less aggressive disease course [18]. Moreover, the long-term effects of antifibrotics on prognosis remain unclear, with both nintedanib and pirfenidone shown to reduce the rate of forced vital capacity (FVC) decline and acute exacerbations, and post hoc pooled analyses suggesting mortality benefit [19-21]. In addition to clinical experience suggesting stabilisation with antifibrotics in a subset of patients, longer term outcomes were recently reported in a 2-year extension of the TOMORROW trial (which had compared 52 weeks of nintedanib versus placebo in IPF [22]), demonstrating mortality in only $25.9 \%$ of patients treated with full-dose nintedanib over the extension period [23].

Survival varies significantly among patients with non-IPF ILD, often exceeding that of IPF by many years, particularly in sarcoidosis, connective tissue disease (CTD)-associated nonspecific interstitial pneumonia (NSIP) and occupational ILD [24-26]. A recent French study grouped several different and specific (non-IPF) ILDs into a single entity termed progressive-fibrosing ILD, defined by $\geqslant 10 \%$ fibrosis on baseline high-resolution computed tomography (HRCT) and clinical disease progression for 2 years prior to study inclusion (by symptoms, lung function and/or HRCT) [27]. Survival was worse in unclassifiable disease or hypersensitivity pneumonitis compared to CTD-ILD, sarcoidosis or other ILDs, but was $>87 \%$ at 2 years and $49.1-80.2 \%$ at 7 years in all groups, indicating survival at the time of initial assessment exceeding the usual thresholds to consider LTx. Furthermore, several recent studies have demonstrated a benefit of antifibrotics in non-IPF ILDs [28-31], suggesting that these agents may stall disease progression and delay or obviate the need for LTx in some.

In contrast, the majority of patients with IPF experience an aggressive course, and the progressive disease in some with non-IPF ILD resembles that of IPF [25, 27, 32-34]. Moreover, the unpredictability and severe consequences of ILD exacerbations should be appreciated, as should the potential for diagnostic uncertainty. Finally, certain barriers to LTx may disproportionately impact candidates with ILD, including small chest cavity in combination with short stature, as well as allosensitisation in those with CTD; although not generally considered when determining LTx referral timing, these factors do have the potential to increase waiting-list times and mortality and thus impact the optimal timing of listing [35-37].

Referral and listing guidelines generalise between forms of ILD and incorporate factors associated with worse outcomes including lower/declining pulmonary function (particularly FVC and diffusing capacity of the lung for carbon monoxide $\left(D_{\mathrm{LCO}}\right)$ ), higher oxygen needs, lower 6-min walk distance (6MWD), pulmonary hypertension (PH), history of pneumothorax or other respiratory hospitalisation, usual interstitial pneumonia pattern on HRCT, frailty and low performance status [13, 27, 38-44] (table 1). Response or lack of response to antifibrotics should be considered. Upcoming guidelines do not alter referral and listing recommendations in patients treated with nintedanib and pirfenidone, but acknowledge the associated challenges in determining timing of LTx [13], and more data are needed to delineate the impacts of antifibrotics on optimal timing of transplantation. Clinical models may improve prediction, but are not widely used in practice [45], and various biomarkers hold promise, but are not yet validated [46]. It 
a)

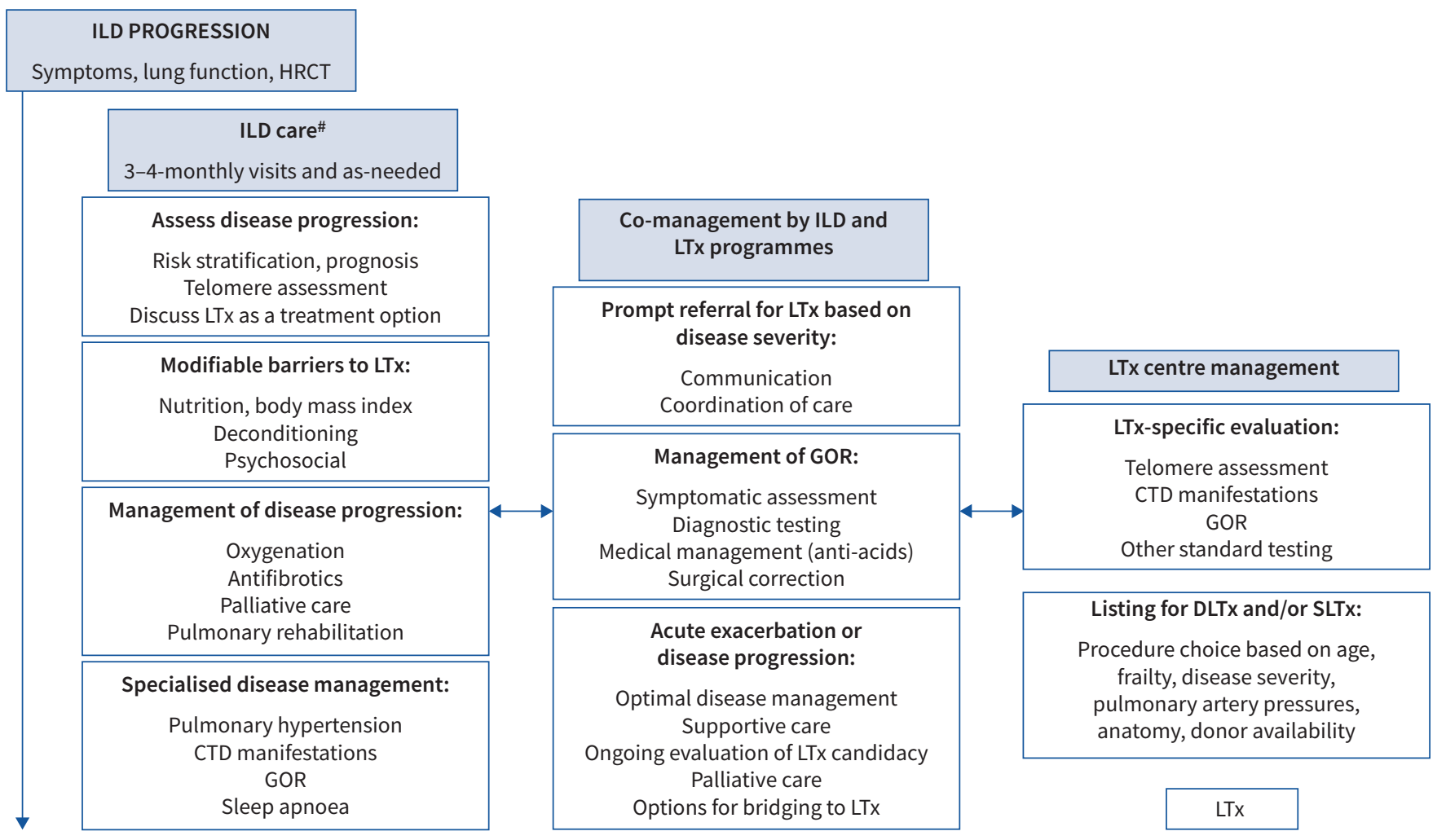

b)

\section{POST-TRANSPLANT}

CLINICAL COURSE

\section{Fundoplication:}

Early for patients with severe pre-transplant GOR Late for new severe GOR

Late for CLAD onset with co-existing GOR

Consider testing for telomere disorders if:

Pre-transplant testing not performed Familial ILD

Young age of ILD onset

Severe haematological, liver or renal complications

\section{Cardiovascular risk reduction:}

Body weight

Nutritional assessment

Pulmonary rehabilitation

Blood pressure

Hyperlipidaemia

Blood glucose

\section{Oesophageal dysmotility including systemic sclerosis}

Consideration of post-pyloric enteral nutrition

Multidisciplinary education to reduce aspiration risks Modified fundoplication may be required for patients with GOR

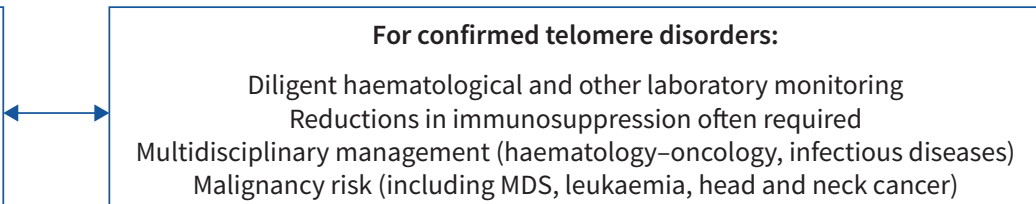

Malignancy risk (including MDS, leukaemia, head and neck cancer)

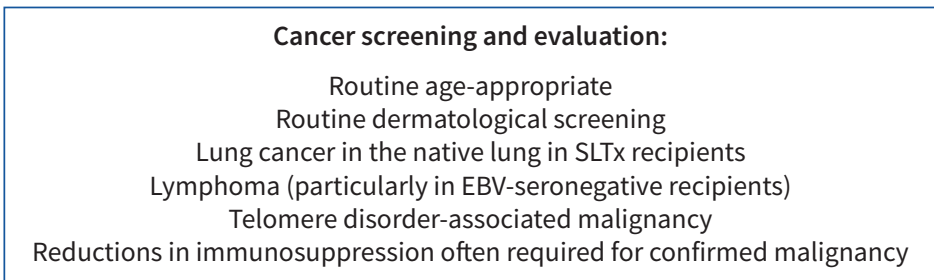

FIGURE 1 Suggested approach for management of progressive interstitial lung disease (ILD) a) before and b) after lung transplantation (LTx). HRCT: high-resolution computed tomography; CTD: connective tissue disease; GOR: gastro-oesophageal reflux; DLTx: double lung transplantation; SLTx: single lung transplantation; CLAD: chronic lung allograft dysfunction; MDS: myelodysplastic syndrome; EBV: Epstein-Barr virus. \#: ILD care should preferably be undertaken by experts in ILD in an experienced centre. 
TABLE 1 Criteria for referral and listing for lung transplantation in patients with interstitial lung disease (ILD)

\begin{tabular}{|c|c|}
\hline Timing of referral ${ }^{\#}$ & Timing of listing \\
\hline Histopathological UIP & $\begin{array}{l}\text { Hospitalisation for respiratory decline, pneumothorax or acute } \\
\text { exacerbation }\end{array}$ \\
\hline Radiographic probable or definite UIP pattern & $\begin{array}{l}\text { Desaturation to }<88 \% \text { on } 6 \mathrm{MWT} \text { or }>50 \mathrm{~m} \text { decline in } 6 \mathrm{MWD} \text { over } \\
6 \text { months }\end{array}$ \\
\hline FVC $<80 \%$ or $D_{\text {LCO }}<40 \%$ pred & $\begin{array}{l}\text { Pulmonary hypertension on right heart catheterisation or } \\
\text { echocardiography }\end{array}$ \\
\hline $\begin{array}{l}\text { Relative decline in pulmonary function over the past } 2 \text { years: } \\
\text { FVC } \geqslant 10 \% \text { or } \\
D_{\mathrm{LCO}} \geqslant 15 \% \text { or } \\
\text { FVC } \geqslant 5 \% \text { with symptomatic or radiographic progression }\end{array}$ & $\begin{array}{l}\text { Absolute decline in pulmonary function over the past } 6 \text { months } \\
\text { despite appropriate treatment: } \\
\text { FVC }>10 \% \text { or } \\
D_{\text {LCO }}>10 \% \text { or } \\
\text { FVC }>5 \% \text { with radiographic progression }\end{array}$ \\
\hline \multicolumn{2}{|l|}{ Any resting or exertional oxygen requirement } \\
\hline \multicolumn{2}{|l|}{ For inflammatory ILDs, disease progression despite treatment } \\
\hline \multicolumn{2}{|c|}{$\begin{array}{l}\text { Referral or listing should be considered if meeting any one criterion. UIP: usual interstitial pneumonia; FVC: forced vital capacity; } D_{\text {Lco: diffusing }} \\
\text { capacity of the lung for carbon monoxide; } 6 \text { MWT: 6-min walk test; 6MWD: } 6 \text {-min walk distance. \#: earlier referral is recommended for patients with } \\
\text { connective tissue disease or familial idiopathic pulmonary fibrosis to address potential extrapulmonary manifestations. Reproduced and modified } \\
\text { from [13] with permission. }\end{array}$} \\
\hline
\end{tabular}

should be noted that FVC decline has been shown to be a less reliable predictor in patients with combined pulmonary fibrosis and emphysema [47].

Acknowledging difficulties in predicting prognosis and higher waiting-list mortality among candidates with ILD compared to other diagnoses [3], the ISHLT emphasises the most conservative strategy of early referral. However, it is important to recognise that specific referral and listing practices vary significantly by ILD and transplant programme, influenced by nation and allocation system, usual waiting times for suitable organs, programme resources, as well as patient volumes and geographic distribution.

\section{Unique risk factors and consideration for LTx in candidates with ILD}

Emphasising the importance of long-term outcomes, guidelines currently under development by the ISHLT recommend that LTx be considered only in candidates with a high ( $>80 \%$ ) likelihood of 5-year post-transplant survival from a general medical perspective, provided there is adequate graft function [13]. Some factors including recent malignancy, life-threatening extrapulmonary organ dysfunction and severe psychosocial problems are considered "absolute contraindications" due to the excessive associated risks of poor outcome (table 2). Accounting for significant variability in handling between transplant centres, the term "relative contraindications" has been replaced by a list of characteristics associated with worse outcomes, with the updated document also commenting on the additive nature of multiple risk factors (table 2) [13]. Many are common in ILD and warrant increased attention, focused management or discussions between referring providers and transplant centres (table 3; see also the section "Management while being considered or after listing for LTx”).

\section{Advanced age in IPF}

Age remains a controversial selection criterion for LTx. Based on the ethical principles of justice and utility, the international transplant community has generally expressed a preference to prioritise organ allocation to younger patients $[13,48]$, and this may be particularly important in programmes and nations with the most pronounced donor shortages. Published literature reports worse survival in recipients older than 65-70 years $[1,49,50]$, and elderly recipients appear to be at greater risk of malignancy, vascular events, drug toxicity and cognitive decline $[51,52]$. Previous guidelines classified age $>65$ years with low physiological reserve as a relative contraindication to LTx, commenting also that patients aged $>75$ years are unlikely to be candidates [14].

Recent literature is more encouraging in the elderly, particularly pertaining to short-term LTx outcomes, where 1-year post-transplant survival appears comparable between recipients aged 70-79 years versus 6069 years [50]. With an ageing population and increasing experience, the proportion of lung transplants performed in elderly patients is increasing. Worldwide data show an increase in the proportion of LTx recipients aged $>65$ years from $2.6 \%$ in 2004 to $17 \%$ in 2016 [51]. The trend appears most pronounced in the USA, where $>30 \%$ of candidates on the waiting list are now aged $>65$ years [3]. This population 
TABLE 2 Risk factors for adverse post-transplant outcomes in candidates for lung transplantation

\begin{tabular}{|c|c|c|}
\hline General & High or substantially increased risk & Absolute contraindications \\
\hline GFR $40-60 \mathrm{~mL} \cdot \mathrm{min}^{-1} \cdot 1.73 \mathrm{~m}^{-2}$ & Severe $C A D$ requiring $C A B G$ at transplant & Malignancy with high risk of death or recurrence \\
\hline LV ejection fraction $40-50 \%$ & Significant cerebrovascular disease & multi-organ transplant \\
\hline Peripheral vascular disease & Severe oesophageal dysmotility & Acute coronary syndrome within 30 days (excluding \\
\hline Connective tissue disease & Untreatable haematological disorders (bleeding & demand ischaemia) \\
\hline Bone marrow dysfunction & $\mathrm{BMI} \geqslant 35 \mathrm{~kg} \cdot \mathrm{m}^{-2}$ & dysfunction unless being considered for multi-organ \\
\hline Osteoporosis & $\mathrm{BMI}<16 \mathrm{~kg} \cdot \mathrm{m}^{-2}$ & transplant \\
\hline $\mathrm{BMI} 30-34.9 \mathrm{~kg} \cdot \mathrm{m}^{-2}$ & Limited functional status with poor rehabilitation & Acute liver failure \\
\hline BMI $16-17 \mathrm{~kg} \cdot \mathrm{m}^{-2}$ & potential & Acute renal failure with rising creatinine or on dialysis \\
\hline Frailty & Psychiatric, psychological or cognitive conditions with & and low likelihood of recovery \\
\hline Hypoalbuminaemia & potential to interfere with medical adherence & Active extrapulmonary infection including septic shock \\
\hline load & Burkholderia cenocepacia or gladioli infection & Repeated episodes of nonadherence without evidence of \\
\hline $\begin{array}{l}\text { Previous thoracic surgery } \\
\text { including pleurodesis }\end{array}$ & $\begin{array}{l}\text { Hepatitis B or C infection with detectable viral load } \\
\text { and liver fibrosis }\end{array}$ & $\begin{array}{l}\text { improvement } \\
\text { Active substance use or dependence including current }\end{array}$ \\
\hline Mechanical ventilation & Chest wall or spinal deformity expected to cause & tobacco use, vaping, marijuana smoking or intravenous \\
\hline Re-transplantation & restriction after transplant & drug use \\
\hline & Extracorporeal life support & Other severe uncontrolled medical condition expected to \\
\hline & $\begin{array}{l}\text { Re-transplantation for restrictive CLAD, } \\
\text { antibody-mediated rejection or within } 1 \text { year } \\
\text { following initial lung transplant }\end{array}$ & limit survival after transplant \\
\hline
\end{tabular}

largely comprises patients with IPF, and 2016 data show that $>40 \%$ of IPF transplants are now in patients aged $>65$ years [51].

More data are needed to better risk-stratify older patients with IPF undergoing transplant. This is especially important in the antifibrotic era, where slowing of disease progression may delay the need for LTx in a subset of patients, and in turn lead to encroachment upon programmatic age limits for transplant. A recent study of 5815 patients aged $>65$ years ( $70 \%$ with restrictive lung disease) demonstrated that increasing age strata, creatinine, bilirubin, hospitalisation at time of transplant, and pre-transplant steroid use were all associated with increased mortality [53]. Other literature focuses on differentiating biological from chronological age, incorporating sarcopenia and frailty, each of which has been independently associated

TABLE 3 Common risk factors for adverse post-lung transplant outcomes in candidates with interstitial lung disease

Advanced age

Overweight status

Telomere biology disorders

Prior thoracic surgery

Limited functional status, deconditioning, frailty

Gastro-oesophageal reflux

High-risk atherosclerotic disease

Connective tissue disease manifestations

Corticosteroids, other immunosuppressants

Acute exacerbations

Active mechanical ventilation 
with worse outcomes [54]. Ultimately, no absolute upper age limit for LTx is endorsed by the ISHLT, and candidacy in elderly patients remains a centre-specific decision [13].

\section{Overweight status}

Biological factors, reduced activity and/or corticosteroids lead to weight gain in many with advanced ILD. One study from the USA of 5978 LTx recipients showed that $67 \%$ of the 1246 transplanted patients with ILD were overweight (body mass index $(\mathrm{BMI}) \geqslant 25 \mathrm{~kg} \cdot \mathrm{m}^{-2}$ ) prior to LTx. Compared to normal-weight recipients, those who were overweight or obese had a $15 \%$ or $22 \%$ higher multivariable-adjusted rate of post-transplant death, respectively [55]. In addition to improving pre-transplant symptoms, weight loss before LTx in overweight candidates has been associated with dose-response improvements in post-transplant survival [56], and many transplant programmes utilise BMI thresholds of $30-35 \mathrm{~kg} \cdot \mathrm{m}^{-2}$ as criteria for active listing.

\section{CTD-associated ILD}

LTx has been used for advanced lung disease in rheumatoid arthritis, mixed CTD, systemic sclerosis, Sjogren syndrome, systemic lupus erythematosus, polymyositis/dermatomyositis/antisynthetase syndrome and pulmonary vasculitis. Although data are limited in CTD-ILD, several cohort studies report post-transplant survival similar to IPF, with no differences in primary graft dysfunction or rejection rates [57-60]. Functional status has been shown to improve [58], and recurrent or progressive nonpulmonary disease after LTx appears to be rare [57, 59, 61]. Even in systemic sclerosis, where some may be considered ineligible for LTx due to aspiration risks, several studies show post-transplant survival similar to IPF without increased risk of chronic lung allograft dysfunction (CLAD) [62-66].

It should be recognised that available studies on LTx for CTD are retrospective and limited by selection bias. In this context, the ISHLT considers CTD to be a risk factor for poorer outcomes and recommends screening for extrapulmonary disease in collaboration with rheumatology when possible [13]. Although post-transplantation immunosuppression generally renders extrapulmonary inflammatory disease quiescent, efforts should be made to control pre-transplant disease at the lowest levels possible to reduce peri-operative infectious risks, while also ensuring that any nonreversible disease does not pose excessive threat to post-transplant outcomes or rehabilitation potential. Systemic sclerosis with severe oesophageal dysmotility may be considered a contraindication at some centres; assessment of swallowing and oesophageal function is crucial, and patients should also undergo evaluation for skin thickening, digital ulceration, renal insufficiency and cardiomyopathy. For inflammatory myopathies, comprehensive cancer screening is required [13, 60]. Comprehensive ISHLT guidelines on LTx for CTD have recently been published [13].

\section{Considerations in other ILDs including sarcoidosis}

LTx is an option for several other ILDs including Langerhans cell histiocytosis [67], occupational ILD including silicosis [68, 69], pleuroparenchymal fibroelastosis (PPFE) [70], chronic hypersensitivity pneumonitis [71] and sarcoidosis. Sarcoidosis is the most common of these less-frequent indications for LTx, accounting for 2.4\% of worldwide transplants between 1995 and 2018 [1]. LTx candidacy in sarcoidosis is generally approached similarly to other ILDs, with the addition of careful pre-transplant screening for conductive and/or infiltrative cardiac disease based on the clinical scenario [72]. Patients with advanced cardiac dysfunction may require heart-lung transplantation, with sarcoidosis accounting for $1.9 \%$ of worldwide heart-lung transplants between 1998 and 2018 [1]. Transplant for sarcoidosis appear to yield similar outcomes compared to the general transplant population [72, 73]. One study analysed 695 patients with sarcoidosis transplanted between 1987 and 2012 and found no difference in survival or bronchiolitis obliterans syndrome (BOS) compared to nonsarcoidosis controls, with the sarcoidosis cohort having a median survival of 63.1 months and a 10-year survival of $30 \%$ [74]. Sarcoidosis does recur in the allograft in up to $35 \%$ of lung transplants, but rarely impacts clinical outcomes (see also the section “Outcomes and considerations after LTx for ILD”) [75].

Although data are limited, other ILDs have also been shown to have similar, if not better, survival after LTx compared to IPF and other control groups [71]. Evaluation of LTx candidacy is also similar, although surgical complexity can be increased in those with dense pleural adhesions. For example, one study compared outcomes of LTx for occupational lung disease versus other diagnoses, and demonstrated similar long-term survival, but a higher need for cardiopulmonary bypass and delayed chest closure in the occupational lung disease cohort [69]. PPFE, presenting either as its own entity or co-existing with other patterns of ILD, can be particularly challenging operatively, with dense adhesions often leading to thoracic contraction and increased bleeding risk [76]. LTx for PPFE or other disorders associated with dense pleural adhesions should be performed only in experienced centres [69, 76]. 
Telomere disorders (pre-transplant considerations)

Chromosomal telomeres protect against loss of genetic information during normal cell division. Critical shortening, often associated with specific mutations in telomere maintenance (including telomerase (TERC/ TERT)), can lead to cell-cycle arrest with associated bone marrow failure and cancer predisposition [77]. A tendency toward both haematological and other forms of cancer, including of the head and neck, is reported [78]. In addition, telomere disorders have been implicated in ILD pathogenesis. A leukocyte telomere length < 10 th percentile is found in up to $25 \%$ of patients with sporadic and $37 \%$ of familial IPF [79], with disorders also recognised in several other forms of ILD [80]. Pre-transplant, telomere shortening is associated with earlier age of presentation and a progressive phenotype [81], and predicts poor response to immunosuppressants in IPF [82].

Reduced telomere length has been linked with worse post-transplant outcomes. Among 86 patients transplanted for ILD, one study demonstrated that pre-transplant telomere length $<10$ th percentile was independently associated with worse survival (hazard ratio 10.9, 95\% CI 2.7-44.8; p=0.001) and higher risks of primary graft dysfunction and CLAD [83]. Haematological and several other post-transplant medical complications are also more common in this cohort [81, 84-86]. With these associations in mind, haematological abnormalities in the context of telomere disorders are now recognised by the ISHLT as a risk factor for poor LTx outcomes [13]. Testing for telomere length and the associated mutations in candidates with ILD is now performed in some centres and may be particularly useful in early-onset or familial ILD. More data are needed to determine whether and how best to integrate testing into the routine pre-transplant evaluation, but it may assist in determining pre-transplant prognosis, risk-stratifying candidates, and predicting post-transplant complications (see also the section "Outcomes and considerations after LTx for ILD”).

\section{Management while being considered or after listing for LTx}

In addition to determining timing of LTx referral (and listing), management of progressive ILD should take place in an experienced ILD centre and requires a comprehensive approach aimed at 1) slowing disease progression and improving symptoms; 2) mitigating risks to improve the likelihood of successful LTx; and 3) optimising candidacy for LTx (figure 1). If the ILD expert is different from the lung transplant pulmonologist, the teams must work in a concerted manner to optimise care and communication (figure 1). Coordination of care may be facilitated if the ILD and transplant pulmonologists are at the same centre, but this may not be required, assuming frequent and close communication can be achieved.

Many recommendations from the ATS/ERS/JRS/ALAT 2011 and 2015 IPF management guidelines apply broadly to advanced ILD, including regular assessment of oxygenation, consideration of antifibrotics, and pulmonary rehabilitation [10,11]. Palliative care should be considered and advance directives addressed while the candidate is an outpatient, and these steps should not be construed as mutually exclusive from treatment-oriented care including LTx $[87,88]$. Psychosocial support may be valuable, and caregiver and financial planning are required prior to LTx to improve the likelihood of successful outcome.

Finally, evaluation for and management of common comorbidities can be beneficial, including obstructive sleep apnoea, coronary artery disease (CAD), gastro-oesophageal reflux (GOR), venous thromboembolism and associated $\mathrm{PH}[89,90]$. For patients with $\mathrm{PH}$, sildenafil, including in a placebo-controlled trial of 274 IPF patients with $D_{\text {LCO }}<35 \%$, has been shown not to improve dyspnoea or 6MWD [91], and received a conditional recommendation against their use in the 2015 guidelines [11]. However, PH can guide transplant timing and appears to be common in this population, with one study showing right ventricular dysfunction in $>40 \%$ of those with IPF and $D_{\text {LCO }}<35 \%$ [91], and another showing pre-transplant mean pulmonary artery pressure $>40 \mathrm{mmHg}$ in nearly $20 \%$ of patients with restrictive lung disease who underwent double LTx (DLTx) [92]. Functional 6MWD benefits have been demonstrated with sildenafil in IPF patients with right ventricular dysfunction [93]. From a transplant perspective, PH is associated with increased risk of primary graft dysfunction and early post-operative mortality after LTx and its presence impacts surgical planning [94, 95], use of mechanical circulatory support and anaesthetic management, although it is unknown how pre-transplant treatment impacts these considerations. Therefore, evaluation for $\mathrm{PH}$ should be considered in progressive ILD, particularly in patients with suggestive signs exceeding those expected from their lung disease alone, or in those with systemic sclerosis or other CTDs in which an overlapping component of vasodilator-responsive (World Health Organization group 1) PH is more likely [96, 97].

\section{Relative risks associated with ILD pharmacotherapies}

Specific treatments may impact peri-operative risks in ILD patients approaching LTx. Chronic, high-dose corticosteroids in particular may increase wound healing complications and risk of anastomotic dehiscence, 
and one study demonstrated increased mortality among 62 patients (38\% with ILD) treated with pre-transplant prednisone doses $>0.42 \mathrm{mg} \cdot \mathrm{kg}^{-1} \cdot \mathrm{day}^{-1}$ [98]. Other data suggest that doses $<40 \mathrm{mg}$ or $0.3 \mathrm{mg} \cdot \mathrm{kg}^{-1} \cdot$ day $^{-1}$ are probably safe [99]. Based on potential risks, many LTx programmes consider maintenance prednisone-equivalent doses $>20 \mathrm{mg} \cdot \mathrm{day}^{-1}$ to be a contraindication (excluding augmented doses for acute exacerbations), and discussions between ILD and transplant programmes on specific corticosteroid policies are necessary. There are no data on the impact of other immunomodulating agents on LTx outcomes, but in general it is best to limit immunosuppressants for ILD to the lowest effective doses while a patient is listed for transplant.

Lastly, despite early attention, recent studies have not demonstrated differences in survival, anastomotic dehiscence or other complications among ILD patients treated with pre-transplant pirfenidone or nintedanib $[100,101]$. The use of antifibrotics leading up to the day of LTx is not considered a contraindication.

\section{Proactive management of obesity and deconditioning}

As described earlier, overweight status is common in patients with ILD approaching LTx. Nutritional counselling and appropriate weight loss can increase the likelihood of successful LTx [56] and improve candidacy, while also potentially improving pre-transplant symptoms. Deconditioning, reduced functional status, frailty and sarcopenia have also been shown to impact pre-transplant trajectory and post-transplant outcomes [102-105]. All appear to be common in advanced ILD, with frailty demonstrated in 30\% of candidates with restrictive lung disease [103, 106, 107], and small studies showing reduced muscle mass by imaging criteria in $20-40 \%$ of candidates [105, 108]. Frailty and impaired functional status are considered risk factors for poor outcomes with LTx [13], and patients with advanced ILD warrant a thorough assessment of conditioning and functional status. Pulmonary rehabilitation has been associated with improved (pre-transplant) symptoms, quality of life and 6MWD, along with more favourable early post-transplant outcomes [13, 109, 110]. It should be considered in all patients with advanced ILD and may be required for LTx.

\section{Anti-reflux surgery for abnormal GOR}

GOR has been demonstrated in up to $90 \%$ of people with IPF and has been implicated in ILD pathogenesis [111-113]. The impact of GOR may be amplified in those with co-existing gastrointestinal dysmotility, most notably in systemic sclerosis [114, 115]. In the WRAP-IPF study, 58 patients with IPF and FVC $>50 \%$ predicted (mean $76.5 \%$ pred) were randomised to laparoscopic fundoplication versus medical management alone. There was no difference in FVC change over 48 weeks, but the surgical cohort had numerically fewer acute exacerbations, respiratory hospitalisations and deaths, without major complications [116].

Reflux and oesophageal motility evaluation is generally required by transplant programmes during evaluation based on associations between GOR and oesophageal dysfunction and post-transplant early allograft injury, infection, acute rejection and CLAD [117-119]. Pre- or early post-transplant fundoplication has been shown to mitigate these risks [120,121]. Although pre-transplant surgery probably carries increased risks compared to those with less severe ILD, it has been shown to be safe in well-selected patients approaching LTx, including in one cohort with mean FVC 50\% pred [120]. Surgical management may serve several purposes, including slowing pre-transplant disease progression, fulfilling candidacy requirements and improving post-transplant outcomes, although more data are needed, especially in advanced ILD. It should be noted that patients with co-existing GOR and oesophageal dysmotility may require modified (Toupet) fundoplication. Ultimately, surgical decisions are generally made on a case-by-case basis in multidisciplinary fashion.

\section{Pre-transplant acute exacerbations}

Most literature on acute ILD exacerbations pertains to IPF (AE-IPF), defined as acute (typically less than 1 month's duration) respiratory deterioration with widespread alveolar abnormality, and exclusion of alternative diagnoses including pulmonary oedema [122]. The prognosis of AE-IPF is poor, with in-hospital mortality nearly $50 \%$ and as high as $90 \%$ in those requiring mechanical ventilation [10], along with a median survival following AE-IPF of only 3-4 months [122]. Corticosteroids may be beneficial in some cases including non-IPF ILD, but supportive evidence in AE-IPF is limited, and without other effective treatments management is largely supportive.

For listed patients, data from the USA show that waiting-list mortality is highest for candidates with restrictive lung disease and with lung allocation scores (LAS) $\geqslant 50$, at 29.7 and 121.8 deaths per 100 waitlist-years [3], respectively. Many deaths are attributable to acute exacerbations, but transplant in the setting of AE-IPF is also associated with worse outcomes. A 2018 analysis of 89 listed IPF patients 
showed 1- and 3-year post-transplant survival of $71 \%$ and $60 \%$, respectively, for those transplanted in the midst of an AE-IPF, compared to $94 \%$ and $90 \%$ for those with stable pre-transplant disease [123]. This and other studies have documented an association between higher LAS at transplant and worse post-transplant outcomes [124], further reinforcing the need for timely transplant referral in ILD.

During an acute exacerbation, close communication with a LTx centre is required to review candidacy and listing status. Currently $>60 \%$ of worldwide lung transplants are allocated based on the LAS, including in Eurotransplant and the USA [125], and scores should be updated upon presentation and during exacerbations. Some nations use other forms of high-emergency allocation systems with varying criteria that a patient may qualify for during acute exacerbations, a practice that has been shown to reduce waiting-list mortality $[125,126]$.

Potential options for bridging with mechanical support should also be reviewed. With improvements in technologies and experience, extracorporeal life support (ECLS) bridging is being increasingly used with improving outcomes [127, 128]. In a 2018 propensity-matched analysis, 49 patients (mean age 44 years; 29 (59\%) with restrictive lung disease) bridged to LTx with mechanical ventilation plus ECLS were compared with unbridged controls, as well as a cohort bridged with mechanical ventilation alone [127]. 1-year post-transplant survival was $79.5 \%$ in those bridged with mechanical ventilation plus ECLS, which was not statistically different from controls. However, bridging is resource-intensive and certainly an important risk factor for poor post-transplant outcomes [13]. Patient selection is critical, with outcomes having shown to be best in experienced centres, age $\leqslant 40$ years, awake/ambulatory systems and shorter bridging duration [129-131]. Extrapulmonary organ dysfunction and uncontrolled sepsis are contraindications, and the ISHLT emphasises that patients presenting de novo (without previous evaluation for LTx) represent higher-risk candidates [13, 14].

Single versus double LTx for ILD

The growth in worldwide LTx volume over the past two decades is largely composed of DLTx, which comprised $81 \%$ of total transplants in 2018, compared to only 50\% in 2000 [1]. That said, the decision on single LTx (SLTx) versus DLTx continues to garner debate in ILD. SLTx provides an opportunity to serve two recipients, a very important advantage given the growing supply-demand mismatch in LTx in the modern era. Moreover, in patients who may be candidates for SLTx or DLTx, studies have demonstrated that listing for either option, as opposed to only DLTx, is associated with decreased waiting-list mortality and increased transplant rate, without compromising 1- or 5-year post-transplant survival [132-134]. Surgically, compared to DLTX, SLTx leads to decreased use of cardiopulmonary bypass, operative and ischaemic times, and duration of mechanical ventilation and intensive care unit stays, factors that may be particularly advantageous for older or more frail patients $[135,136]$. SLTx has shown comparable or even superior post-transplant outcomes in the first 3-12 months and in older patients, with lower rates of death from primary graft dysfunction [136, 137]. Longer-term, despite lower lung function, recipients of SLTx versus DLTx have been shown to have similar improvements in health-related quality of life [138].

Other literature supports DLTx as the optimal procedure choice in ILD. Among >60 000 transplants (19922017), the ISHLT median survival after DLTx was 7.8 years, compared to 4.8 years after SLTx [1]. In 4134 patients with IPF, a 2015 analysis demonstrated adjusted median survival of 65.2 months versus 50.4 months $(\mathrm{p}<0.001)$ with DLTx and SLTx, respectively [139]. A 2018 analysis confirmed these findings among patients with restrictive lung disease, demonstrating 10 -year survival rates of 55\% versus $32 \%$, respectively [140]. Contrary to earlier reports in older patients, in a 2015 study of nearly 1000 patients with IPF aged $\geqslant 65$ years, DLTx after propensity-matching was associated with no difference in early survival, and significantly improved 5 -year survival $(48.7 \%$ versus $35.2 \%, \mathrm{p}<0.01$ ) compared to SLTx [141]. The potential advantages of DLTx for ILD are probably most pronounced in younger patients, and those with associated PH or higher LAS [140, 142].

Ultimately, a flexible approach is warranted in ILD, with the choice of procedure best determined by individual programmes on a case-by-case basis factoring in age, frailty, overall disease severity including LAS and pulmonary artery pressures, anatomic factors and availability and suitability of donor lung(s).

Outcomes and considerations after LTx for ILD

Although improving, outcomes following LTx are inferior to transplantation of other solid organs, with the majority of deaths related to infections or CLAD [1]. ISHLT registry data show that among ILD recipients surviving $>5$ years, $\sim 25 \%$ of deaths are due to malignancy including lymphoma, and nearly $7 \%$ are due to cardiovascular causes [143]. Although the general management of patients transplanted for ILD is similar 
TABLE 4 Morbidity rates in survivors at 5 years after lung transplantation for interstitial lung disease

Idiopathic interstitial pneumonia \% of survivors with listed diagnosis
Other interstitial lung diseases \% of survivors with listed diagnosis

\begin{tabular}{lcc}
\hline Hypertension & 79.5 & 80.0 \\
Creatinine $>2.5 \mathrm{mg} \cdot \mathrm{dL}^{-1}$ & 35.8 & 34.4 \\
Chronic dialysis or renal & 2.7 & 2.7 \\
$\quad$ transplant & & 57.1 \\
Hyperlipidaemia & 63.4 & 33.2 \\
\hline Diabetes & 37.7 & \\
\hline
\end{tabular}

Data from the International Society for Heart and Lung Transplantation 2016 registry [143].

to the overall LTx population, several medical comorbidities warrant increased attention for their ability to impact morbidity and long-term survival (table 4, figure 1) [143].

\section{Coronary artery disease}

Cardiovascular disease is common in ILD, probably due to inflammation, endothelial injury, lipid abnormalities and/or disease treatments [144, 145]. CAD in particular has increased incidence in IPF and some CTDs including systemic lupus erythematosus and rheumatoid arthritis, where it is recognised as an important cause of mortality [144-147]. The prevalence of CAD is as high as $68 \%$ in IPF patients undergoing cardiac catheterisation during a pre-transplant evaluation [133], and in patients referred for LTx, after adjustment for traditional risk factors fibrotic lung disease has been independently associated with increased CAD risk compared to other diagnoses [148]. Carefully selected patients with CAD can undergo successful LTx without increased mortality, but a vigilant approach is required after transplant to monitor symptoms and optimise cardiovascular risk factors [149].

\section{Gastrointestinal disease}

Many candidates with ILD may be considered for antireflux surgery before LTx [120]. Fundoplication is often considered after LTx if pre-transplant surgery is deemed unsafe, or if a patient develops post-transplant GOR symptoms or lung function decline. For those with early post-transplant GOR, observational studies of mixed populations including ILD have shown antireflux surgery to improve mortality, lung function and freedom from BOS [121, 150-152], with the effects most pronounced if performed early after LTx. Additionally, guidelines recommend considering GOR as a cause of post-transplant pulmonary decline including CLAD [150], where antireflux surgery has been associated with improved lung function [153].

Gastrointestinal dysmotility is common after LTx, with one study showing delayed gastric emptying in $>50 \%$ of patients transplanted for restrictive lung disease [154]. Dysmotility has been associated with increased risk of BOS [155], and although this finding has not been consistent, it can certainly increase symptoms, impact drug absorption and render conventional antireflux surgery unsafe in those with co-existing GOR [13]. Particularly important for CTDs including systemic sclerosis, in experienced centres, carefully selected patients with severe oesophageal dysmotility can have reasonable outcomes after LTx using a cautious, multidisciplinary approach including speech pathology, nutrition and thorough education on GOR and aspiration precautions [62, 64]. After LTx for systemic sclerosis, some centres describe a prolonged nil-per-mouth approach with post-pyloric tube feeding until a patient demonstrates pulmonary stability and adequate swallowing function on objective studies [64]. Others use a time-based approach, extending enteral nutrition to $\geqslant 6$ months post-transplant [65].

\section{Post-transplant complications of telomere biology disorders}

The post-transplant risks related to chromosomal telomere shortening in both sporadic and familial ILD are being increasingly recognised. Anaemia occurs after LTx in nearly all recipients with known telomere shortening and can require recurrent transfusions and/or erythropoietin supplementation [83, 85, 86]. Small studies have shown leukopenia, filgrastim requirement and thrombocytopenia in up to $83 \%$, $33 \%$ and $88 \%$ of patients, respectively [84, 86]. Myelodysplastic syndrome has been reported and should be considered in refractory cases [85], and general cancer risk also appears to be increased [78]. Infectious complications are common, including cytomegalovirus, for which treatment can be challenging, particularly given the associated bone marrow toxicities [85]. Chronic renal disease and elevations in transaminase levels have 
a)

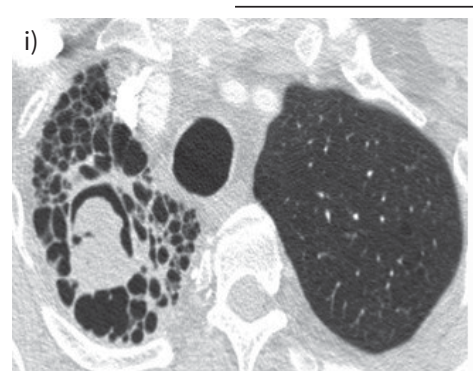

12 years

b)

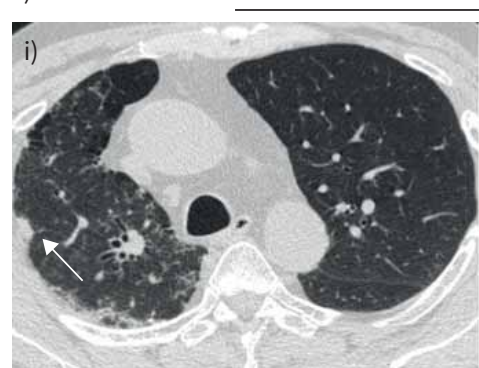

21 months

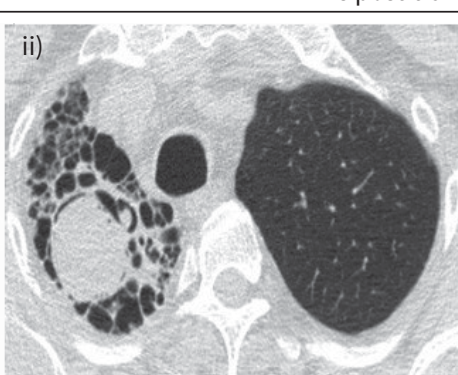

13 years

Time post-transplant

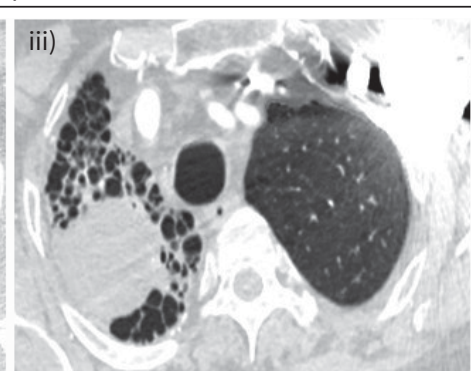

14 years

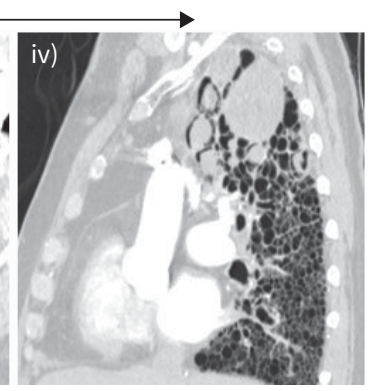

14 years

Time post-transplant

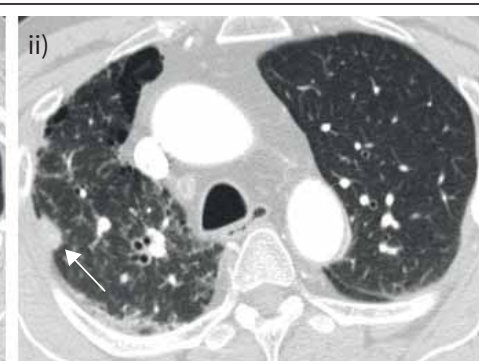

24 months

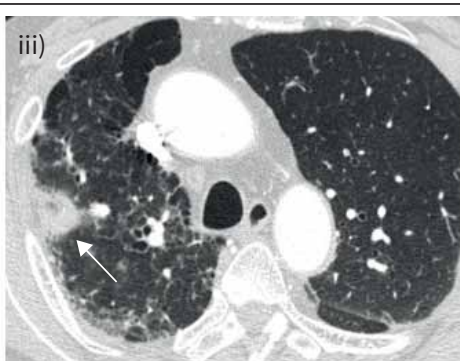

26 months

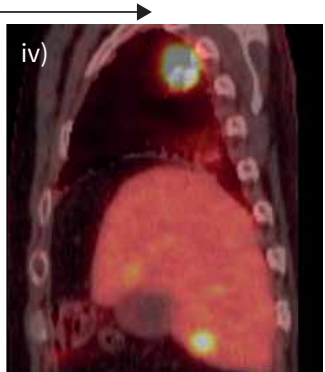

27 months

FIGURE 2 Examples of post-transplant complications in the native fibrotic lung after single lung transplantation (SLTx). a) Images from a 57-year-old male 12 years after left SLTx for familial idiopathic pulmonary fibrosis; i) demonstrates a mycetoma in the native right upper lobe on axial computed tomography images. Bronchoalveolar lavage cultures from the (native) right upper lobe as well as from the (allograft) left upper lobe grew Aspergillus fumigatus. He was treated with prolonged voriconazole, but surveillance imaging showed increasing size of the mycetoma at ii) 13 and iii) 14 years post-transplant, with iv) sagittal imaging also demonstrating several new, smaller mycetomas. b) Images from a 62-year-old male 21 months after left SLTx for rheumatoid arthritis-associated interstitial lung disease. On axial computed tomography, i) demonstrates a small nodule versus focus of scarring superimposed upon underlying fibrosis in the native lung (arrow). ii, iii) Surveillance imaging demonstrated evolution into a clear nodule which increased in size over 5 months (arrows). iv) Positron emission tomography (sagittal image) confirmed a hypermetabolic right upper lobe nodule, along with multiple hypermetabolic lesions in the liver consistent with metastases. Percutaneous biopsy of the lung nodule confirmed adenocarcinoma. The patient died at 29 months post-transplant due to complications from brain metastases.

been demonstrated in up to $80-85 \%$ of patients [86]. Together, the various complications often lead to intolerance of immunosuppression, most frequently leading to reductions or complete cessation of the antiproliferative agent [85, 86].

Somewhat paradoxically, patients with ILD and known telomere shortening also appear to be at greater risk of CLAD after LTx, with one study showing incidence of $50 \%$ versus $23 \%(p=0.022)$ in recipients with telomere length less than or greater than the 10th percentile, respectively [83]. The authors suggested potential mechanisms for this finding including general immune dysregulation, altered adaptive immunity and propensity for lower respiratory tract infections driving airway inflammation [83], and it is also conceivable that reduced immunosuppression itself may contribute.

Optimal management after LTx in patients with telomere disorders is unclear, but requires closer monitoring for haematological, malignant and other complications, and reduced immunosuppression is often required. Consultation from a haematologist familiar with telomere disorders should be considered, and care may also require co-management with infectious diseases, particularly in cases of persistent or resistant cytomegalovirus.

\section{Native lung considerations in SLTX recipients}

Progression of fibrotic lung disease in the native lung is common anecdotally and was shown to occur in all patients receiving SLTx for IPF in one small series [156]. Despite this, hypoxic vasoconstriction leads to appropriate diversion of 60-90\% of blood flow to the allograft in most ILD patients receiving SLTx [157], lessening the clinical importance of native lung function after transplant. 
Several specific complications in the native fibrotic lung have been reported after SLTx for ILD including infections, mycetomas, pneumothorax and bronchopleural fistula [7, 157, 158] (figure 2). Most importantly, with fibrotic disease carrying a five-fold increased risk of malignancy compared to the general population that may be amplified with post-transplant immunosuppression, native lung cancers have been reported in up to $10 \%$ of ILD SLTx recipients [158-160]. Detection can be difficult due to fibrosis and outcomes are poor, with reported survival after diagnosis $<1$ year $[160,161]$. With these risks in mind, some programmes perform routine CT imaging in SLTx recipients, though more data are needed to guide the optimal approach.

Disease recurrence in the allograft

Recurrence of native disease in the lung allograft is rare, probably due to post-transplant immunosuppression, and, particularly in older recipients a relatively short average graft survival compared to typical disease onset. One study reported that only 1\% of 1934 LTx recipients developed disease recurrence [75]. Incidence was highest in sarcoidosis, with nine (35\%) out of 26 developing recurrent radiographic or pathological signs. In a more recent analysis, among 30 recipients of LTx for sarcoidosis, histological and radiographic recurrence were documented in seven (23.3\%) and one (0.4\%), respectively [162]. Interestingly, acute rejection rate was significantly lower in those that developed recurrent sarcoidosis, and recurrence did not impact 1- or 5-year survival. Recurrence of hypersensitivity pneumonitis [71], Langerhans cell histiocytosis [75], desquamative interstitial pneumonitis [163] and NSIP have all been reported in the allograft, and an index of suspicion should be maintained after LTx for these entities [164], but clinically relevant disease is quite rare. Recurrence of IPF in the allograft lung has not been reported to date.

\section{Conclusions}

LTx offers the potential for vastly improved quality and duration of life for patients with advanced and/or progressive fibrotic ILD. With an increasing proportion of transplants for ILD it is important for both general and transplant pulmonologists to appreciate the complexities specific to this population that impact candidacy, pre-transplant risks and post-transplant management. In most cases, disease progression should prompt early referral to a LTx centre concurrent with care at an ILD centre to guide slowing the fibrotic lung disease, stabilising overall clinical status and optimising a candidate for LTx. Candidacy and procedure choice remain influenced by centre-specific policies. Recognition of common comorbidities in ILD is also required after LTx to optimise the chance of long-term survival.

\section{Future directions}

Further study is needed to optimise care and improve outcomes with LTx for ILD. The shortage of adequate donor lungs is especially important to recognise with increasing transplant volumes and proportion of transplants for ILD. Particularly with antifibrotics, improved methods are needed to determine prognosis in candidates with various types of ILD and identify those in greatest need of LTx. The use of marginal lungs, including with ex vivo lung perfusion, and how expanded-criteria lungs may be used in sicker candidates with ILD warrants attention. Serving two candidates with SLTx (versus DLTx) also provides an opportunity to reduce the number of patients dying without transplant; determining which patients may be best suited for SLTx, how to ensure that both donor lungs are used and the optimal management strategies after SLTx all represent areas of interest.

Finally, the transplant community is transitioning toward higher-risk, sicker candidates, and more data are needed to guide optimal practice in those with ILD and advanced age, frailty, CTD-associated issues including oesophageal dysmotility, respiratory failure requiring bridging and telomere biology disorders. This includes not only candidacy for LTx, but also personalising post-transplant care including immunosuppression to reduce infectious and malignant complications while still protecting against CLAD. Based on the antiproliferative characteristics of antifibrotic agents, treatment clinical trials with antifibrotic agents for CLAD are worthwhile considerations to pursue biological plausibility.

Provenance: Commissioned article, peer reviewed.

Conflict of interest: S.G. Kapnadak has nothing to disclose. G. Raghu reports personal fees and other funding from Boehringer Ingelheim, and other funding from Roche-Genentech, outside the submitted work.

\section{References}

$1 \quad$ Chambers DC, Cherikh WS, Harhay MO, et al. The International Thoracic Organ Transplant Registry of the International Society for Heart and Lung Transplantation: thirty-sixth adult lung and heart-lung transplantation report - 2019; focus theme: donor and recipient size match. J Heart Lung Transplant 2019; 38: 1042-1055. 
2

Chambers DC, Zuckermann A, Cherikh WS, et al. The International Thoracic Organ Transplant Registry of the International Society for Heart and Lung Transplantation: 37th adult lung transplantation report - 2020; focus on deceased donor characteristics. J Heart Lung Transplant 2020; 39: 1016-1027.

Valapour M, Lehr CJ, Skeans MA, et al. OPTN/SRTR 2018 annual data report: lung. Am J Transplant 2020; 20: Suppl. s1, 427-508.

Lehr CJ, Skeans M, Valapour M. Validating thoracic simulated allocation model predictions for impact of broader geographic sharing of donor lungs on transplant waitlist outcomes. J Heart Lung Transplant 2020; 39: $433-440$.

Mooney JJ, Bhattacharya J, Dhillon GS. Effect of broader geographic sharing of donor lungs on lung transplant waitlist outcomes. J Heart Lung Transplant 2019; 38: 136-144.

Riou J, Boëlle PY, Christie JD, et al. High emergency organ allocation rule in lung transplantation: a simulation study. ERJ Open Res 2017; 3: 00020-2017.

Thabut G, Mal H, Castier Y, et al. Survival benefit of lung transplantation for patients with idiopathic pulmonary fibrosis. J Thorac Cardiovasc Surg 2003; 126: 469-475.

Vock DM, Durheim MT, Tsuang WM, et al. Survival benefit of lung transplantation in the modern era of lung allocation. Ann Am Thorac Soc 2017; 14: 172-181.

Hosenpud JD, Bennett LE, Keck BM, et al. Effect of diagnosis on survival benefit of lung transplantation for end-stage lung disease. Lancet 1998; 351: 24-27.

Raghu G, Collard HR, Egan JJ, et al. An official ATS/ERS/JRS/ALAT statement: idiopathic pulmonary fibrosis: evidence-based guidelines for diagnosis and management. Am J Respir Crit Care Med 2011; 183: 788-824.

Raghu G, Rochwerg B, Zhang Y, et al. An official ATS/ERS/JRS/ALAT clinical practice guideline: treatment of idiopathic pulmonary fibrosis. an update of the 2011 clinical practice guideline. Am J Respir Crit Care Med 2015; 192: e3-e19.

Glanville AR. Counterpoint: should every patient with idiopathic pulmonary fibrosis be referred for transplant evaluation? No. Chest 2020; 157: 1413-1414.

Leard LE, Holm A, Valapour M, et al. Consensus document for the selection of lung transplant candidates: an update from the International Society for Heart and Lung Transplantation. J Heart Lung Transplant 2021; in press [https://doi.org/10.1016/j.healun.2021.07.005].

Weill D, Benden C, Corris PA, et al. A consensus document for the selection of lung transplant candidates: 2014 - an update from the Pulmonary Transplantation Council of the International Society for Heart and Lung Transplantation. J Heart Lung Transplant 2015; 34: 1-15.

Fernández Pérez ER, Daniels CE, Schroeder DR, et al. Incidence, prevalence, and clinical course of idiopathic pulmonary fibrosis: a population-based study. Chest 2010; 137: 129-137.

Flaherty KR, Toews GB, Travis WD, et al. Clinical significance of histological classification of idiopathic interstitial pneumonia. Eur RespirJ 2002; 19: 275-283.

Bjoraker JA, Ryu JH, Edwin MK, et al. Prognostic significance of histopathologic subsets in idiopathic pulmonary fibrosis. Am J Respir Crit Care Med 1998; 157: 199-203.

Brown AW, Shlobin OA, Weir N, et al. Dynamic patient counseling: a novel concept in idiopathic pulmonary fibrosis. Chest 2012; 142: 1005-1010.

King TE Jr, Bradford WZ, Castro-Bernardini S, et al. A phase 3 trial of pirfenidone in patients with idiopathic pulmonary fibrosis. N Engl J Med 2014; 370: 2083-2092.

Richeldi L, du Bois RM, Raghu G, et al. Efficacy and safety of nintedanib in idiopathic pulmonary fibrosis. $N$ Engl J Med 2014; 370: 2071-2082.

Nathan SD, Albera C, Bradford WZ, et al. Effect of pirfenidone on mortality: pooled analyses and meta-analyses of clinical trials in idiopathic pulmonary fibrosis. Lancet Respir Med 2017; 5: 33-41.

Richeldi L, Costabel U, Selman M, et al. Efficacy of a tyrosine kinase inhibitor in idiopathic pulmonary fibrosis. N Engl J Med 2011; 365: 1079-1087.

Richeldi L, Kreuter M, Selman M, et al. Long-term treatment of patients with idiopathic pulmonary fibrosis with nintedanib: results from the TOMORROW trial and its open-label extension. Thorax 2018; 73: 581-583.

Thomeer MJ, Vansteenkiste J, Verbeken EK, et al. Interstitial lung diseases: characteristics at diagnosis and mortality risk assessment. Respir Med 2004; 98: 567-573.

Cottin V, Hirani NA, Hotchkin DL, et al. Presentation, diagnosis and clinical course of the spectrum of progressive-fibrosing interstitial lung diseases. Eur Respir Rev 2018; 27: 180076.

Park JH, Kim DS, Park IN, et al. Prognosis of fibrotic interstitial pneumonia: idiopathic versus collagen vascular disease-related subtypes. Am J Respir Crit Care Med 2007; 175: 705-711.

Nasser M, Larrieu S, Si-Mohamed S, et al. Progressive fibrosing interstitial lung disease: a clinical cohort (the PROGRESS study). Eur Respir J 2021; 57: 2002718.

Flaherty KR, Wells AU, Cottin V, et al. Nintedanib in progressive fibrosing interstitial lung diseases. $N$ Engl J Med 2019; 381: 1718-1727. 
Maher TM, Corte TJ, Fischer A, et al. Pirfenidone in patients with unclassifiable progressive fibrosing interstitial lung disease: a double-blind, randomised, placebo-controlled, phase 2 trial. Lancet Respir Med 2020; 8: 147-157.

Behr J, Neuser P, Prasse A, et al. Exploring efficacy and safety of oral pirfenidone for progressive, non-IPF lung fibrosis (RELIEF) - a randomized, double-blind, placebo-controlled, parallel group, multi-center, phase II trial. BMC Pulm Med 2017; 17: 122.

Distler O, Highland KB, Gahlemann M, et al. Nintedanib for systemic sclerosis-associated interstitial lung disease. N Engl J Med 2019; 380: 2518-2528.

Wijsenbeek M, Cottin V. Spectrum of fibrotic lung diseases. N Engl J Med 2020; 383: 958-968.

Nunes $\mathrm{H}$, Schubel K, Piver D, et al. Nonspecific interstitial pneumonia: survival is influenced by the underlying cause. Eur Respir J 2015; 45: 746-755.

Alberti ML, Malet Ruiz JM, Fernández ME, et al. Comparative survival analysis between idiopathic pulmonary fibrosis and chronic hypersensitivity pneumonitis. Pulmonology 2020; 26: 3-9.

Ganapathi AM, Mulvihill MS, Englum BR, et al. Transplant size mismatch in restrictive lung disease. Transpl Int 2017; 30: 378-387.

Tague LK, Witt CA, Byers DE, et al. Association between allosensitization and waiting list outcomes among adult lung transplant candidates in the United States. Ann Am Thorac Soc 2019; 16: 846-852.

Sell JL, Bacchetta M, Goldfarb SB, et al. Short stature and access to lung transplantation in the United States. A cohort study. Am J Respir Crit Care Med 2016; 193: 681-688.

Raghu G, Ley B, Brown KK, et al. Risk factors for disease progression in idiopathic pulmonary fibrosis. Thorax 2020; 75: 78-80.

Snyder L, Neely ML, Hellkamp AS, et al. Predictors of death or lung transplant after a diagnosis of idiopathic pulmonary fibrosis: insights from the IPF-PRO Registry. Respir Res 2019; 20: 105.

Hayes D Jr, Black SM, Tobias JD, et al. Influence of pulmonary hypertension on patients with idiopathic pulmonary fibrosis awaiting lung transplantation. Ann Thorac Surg 2016; 101: 246-252.

Collard HR, King TE Jr, Bartelson BB, et al. Changes in clinical and physiologic variables predict survival in idiopathic pulmonary fibrosis. Am J Respir Crit Care Med 2003; 168: 538-542.

Ratwani AP, Ahmad KI, Barnett SD, et al. Connective tissue disease-associated interstitial lung disease and outcomes after hospitalization: a cohort study. Respir Med 2019; 154: 1-5.

Kirkil G, Lower EE, Baughman RP. Predictors of mortality in pulmonary sarcoidosis. Chest 2018; 153 105-113.

du Bois RM, Weycker D, Albera C, et al. Six-minute-walk test in idiopathic pulmonary fibrosis: test validation and minimal clinically important difference. Am J Respir Crit Care Med 2011; 183: 1231-1237.

du Bois RM, Weycker D, Albera C, et al. Ascertainment of individual risk of mortality for patients with idiopathic pulmonary fibrosis. Am J Respir Crit Care Med 2011; 184: 459-466.

Inoue $\mathrm{Y}$, Kaner RJ, Guiot J, et al. Diagnostic and prognostic biomarkers for chronic fibrosing interstitial lung diseases with a progressive phenotype. Chest 2020; 158: 646-659.

Yoon HY, Kim TH, Seo JB, et al. Effects of emphysema on physiological and prognostic characteristics of lung function in idiopathic pulmonary fibrosis. Respirology 2019; 24: 55-62.

Tong A, Howard K, Jan S, et al. Community preferences for the allocation of solid organs for transplantation: a systematic review. Transplantation 2010; 89: 796-805.

Gutierrez C, Al-Faifi S, Chaparro C, et al. The effect of recipient's age on lung transplant outcome. Am J Transplant 2007; 7: 1271-1277.

Hayanga AJ, Aboagye JK, Hayanga HE, et al. Contemporary analysis of early outcomes after lung transplantation in the elderly using a national registry. J Heart Lung Transplant 2015; 34: 182-188.

Courtwright A, Cantu E. Lung transplantation in elderly patients. J Thorac Dis 2017; 9: 3346-3351.

Vadnerkar A, Toyoda $\mathrm{Y}$, Crespo M, et al. Age-specific complications among lung transplant recipients 60 years and older. J Heart Lung Transplant 2011; 30: 273-281.

Mosher CL, Weber JM, Frankel CW, et al. Risk factors for mortality in lung transplant recipients aged $\geqslant 65$ years: a retrospective cohort study of 5,815 patients in the scientific registry of transplant recipients. $J$ Heart Lung Transplant 2020; 40: 42-55.

54 Schweiger T, Hoetzenecker K. Is chronological age still a hard selection criterion for lung transplantation? $J$ Heart Lung Transplant 2021; 40: 99-100.

Lederer DJ, Wilt JS, D'Ovidio F, et al. Obesity and underweight are associated with an increased risk of death after lung transplantation. Am J Respir Crit Care Med 2009; 180: 887-895.

Clausen ES, Frankel C, Palmer SM, et al. Pre-transplant weight loss and clinical outcomes after lung transplantation. J Heart Lung Transplant 2018; 37: 1443-1447.

Park JE, Kim SY, Song JH, et al. Comparison of short-term outcomes for connective tissue disease-related interstitial lung disease and idiopathic pulmonary fibrosis after lung transplantation. $J$ Thorac Dis 2018; 10: 1538-1547. 
Yazdani A, Singer LG, Strand V, et al. Survival and quality of life in rheumatoid arthritis-associated interstitial lung disease after lung transplantation. J Heart Lung Transplant 2014; 33: 514-520.

Courtwright AM, El-Chemaly S, Dellaripa PF, et al. Survival and outcomes after lung transplantation for non-scleroderma connective tissue-related interstitial lung disease. J Heart Lung Transplant 2017; 36: 763-769.

Ameye $\mathrm{H}$, Ruttens $\mathrm{D}$, Benveniste $\mathrm{O}$, et al. Is lung transplantation a valuable therapeutic option for patients with pulmonary polymyositis? Experiences from the Leuven transplant cohort. Transplant Proc 2014; 46: 3147-3153.

Takagishi T, Ostrowski R, Alex C, et al. Survival and extrapulmonary course of connective tissue disease after lung transplantation. J Clin Rheumatol 2012; 18: 283-289.

Sottile PD, Iturbe D, Katsumoto TR, et al. Outcomes in systemic sclerosis-related lung disease after lung transplantation. Transplantation 2013; 95: 975-980.

Miele $\mathrm{CH}$, Schwab K, Saggar R, et al. Lung transplant outcomes in systemic sclerosis with significant esophageal dysfunction. A comprehensive single-center experience. Ann Am Thorac Soc 2016; 13: 793-802.

Crespo MM, Bermudez CA, Dew MA, et al. Lung transplant in patients with scleroderma compared with pulmonary fibrosis. Short- and long-term outcomes. Ann Am Thorac Soc 2016; 13: 784-792.

Chan EY, Goodarzi A, Sinha N, et al. Long-term survival in bilateral lung transplantation for scleroderma-related lung disease. Ann Thorac Surg 2018; 105: 893-900.

Pradère $\mathrm{P}$, Tudorache I, Magnusson J, et al. Lung transplantation for scleroderma lung disease: an international, multicenter, observational cohort study. J Heart Lung Transplant 2018; 37: 903-911.

Wajda N, Zhu Z, Jandarov R, et al. Clinical outcomes and survival following lung transplantation in patients with pulmonary Langerhans cell histiocytosis. Respirology 2020; 25: 644-650.

Hayes D Jr, Hayes KT, Hayes HC, et al. Long-term survival after lung transplantation in patients with silicosis and other occupational lung disease. Lung 2015; 193: 927-931.

Joubert KD, Awori Hayanga J, Strollo DC, et al. Outcomes after lung transplantation for patients with occupational lung diseases. Clin Transplant 2019; 33: e13460.

Ali MS, Ramalingam VS, Haasler G, et al. Pleuroparenchymal fibroelastosis (PPFE) treated with lung transplantation and review of the literature. BMJ Case Rep 2019; 12: e229402.

Kern RM, Singer JP, Koth L, et al. Lung transplantation for hypersensitivity pneumonitis. Chest 2015; 147: 1558-1565.

Meyer KC. Lung transplantation for pulmonary sarcoidosis. Sarcoidosis Vasc Diffuse Lung Dis 2019; 36: 92-107.

Wille KM, Gaggar A, Hajari AS, et al. Bronchiolitis obliterans syndrome and survival following lung transplantation for patients with sarcoidosis. Sarcoidosis Vasc Diffuse Lung Dis 2008; 25: 117-124.

Taimeh Z, Hertz MI, Shumway S, et al. Lung transplantation for pulmonary sarcoidosis. Twenty-five years of experience in the USA. Thorax 2016; 71: 378-379.

Collins J, Hartman MJ, Warner TF, et al. Frequency and CT findings of recurrent disease after lung transplantation. Radiology 2001; 219: 503-509.

George PM, Patterson CM, Reed AK, et al. Lung transplantation for idiopathic pulmonary fibrosis. Lancet Respir Med 2019; 7: 271-282.

Armanios M. Telomeres and age-related disease: how telomere biology informs clinical paradigms. J Clin Invest 2013; 123: 996-1002.

Boscolo-Rizzo P, Da Mosto MC, Rampazzo E, et al. Telomeres and telomerase in head and neck squamous cell carcinoma: from pathogenesis to clinical implications. Cancer Metastasis Rev 2016; 35: 457-474.

Cronkhite JT, Xing C, Raghu G, et al. Telomere shortening in familial and sporadic pulmonary fibrosis. Am J Respir Crit Care Med 2008; 178: 729-737.

Snetselaar R, van Moorsel CHM, Kazemier KM, et al. Telomere length in interstitial lung diseases. Chest 2015; 148: 1011-1018.

Newton CA, Batra K, Torrealba J, et al. Telomere-related lung fibrosis is diagnostically heterogeneous but uniformly progressive. Eur Respir J 2016; 48: 1710-1720.

Newton CA, Zhang D, Oldham JM, et al. Telomere length and use of immunosuppressive medications in idiopathic pulmonary fibrosis. Am J Respir Crit Care Med 2019; 200: 336-347.

Newton CA, Kozlitina J, Lines JR, et al. Telomere length in patients with pulmonary fibrosis associated with chronic lung allograft dysfunction and post-lung transplantation survival. J Heart Lung Transplant 2017; 36: 845-853.

Silhan LL, Shah PD, Chambers DC, et al. Lung transplantation in telomerase mutation carriers with pulmonary fibrosis. Eur Respir J 2014; 44: 178-187.

Borie R, Kannengiesser C, Hirschi S, et al. Severe hematologic complications after lung transplantation in patients with telomerase complex mutations. J Heart Lung Transplant 2015; 34: 538-546.

Tokman S, Singer JP, Devine MS, et al. Clinical outcomes of lung transplant recipients with telomerase mutations. J Heart Lung Transplant 2015; 34: 1318-1324. 

palliative care for patients with respiratory diseases and critical illnesses. Am J Respir Crit Care Med 2008; 177: 912-927.

88 Bonella F, Wijsenbeek M, Molina-Molina M, et al. European IPF Patient Charter: unmet needs and a call to action for healthcare policymakers. Eur Respir J 2016; 47: 597-606.

89 Singh S, Sharma BB, Bairwa M, et al. Management of interstitial lung diseases: a consensus statement of the Indian Chest Society (ICS) and National College of Chest Physicians (NCCP). Lung India 2020; 37: 359-378.

90 Caminati A, Lonati C, Cassandro R, et al. Comorbidities in idiopathic pulmonary fibrosis: an underestimated issue. Eur Respir Rev 2019; 28: 190044.

91 Kolb M, Raghu G, Wells AU, et al. Nintedanib plus sildenafil in patients with idiopathic pulmonary fibrosis. N Engl J Med 2018; 379: 1722-1731.

92 Nasir BS, Mulvihill MS, Barac YD, et al. Single lung transplantation in patients with severe secondary pulmonary hypertension. J Heart Lung Transplant 2019; 38: 939-948.

93 Han MK, Bach DS, Hagan PG, et al. Sildenafil preserves exercise capacity in patients with idiopathic pulmonary fibrosis and right-sided ventricular dysfunction. Chest 2013; 143: 1699-1708.

94 Hayes D Jr, Higgins RS, Black SM, et al. Effect of pulmonary hypertension on survival in patients with idiopathic pulmonary fibrosis after lung transplantation: an analysis of the United Network of Organ Sharing registry. J Heart Lung Transplant 2015, 34: 430-437.

95 Whelan TP, Dunitz JM, Kelly RF, et al. Effect of preoperative pulmonary artery pressure on early survival after lung transplantation for idiopathic pulmonary fibrosis. J Heart Lung Transplant 2005; 24: 1269-1274.

96 Simonneau G, Montani D, Celermajer DS, et al. Haemodynamic definitions and updated clinical classification of pulmonary hypertension. Eur Respir J 2019; 53: 1801913.

97 Nathan SD, Barbera JA, Gaine SP, et al. Pulmonary hypertension in chronic lung disease and hypoxia. Eur Respir J 2019; 53: 1801914.

98 McAnally KJ, Valentine VG, LaPlace SG, et al. Effect of pre-transplantation prednisone on survival after lung transplantation. J Heart Lung Transplant 2006; 25: 67-74.

99 Park SJ, Nguyen DQ, Savik K, et al. Pre-transplant corticosteroid use and outcome in lung transplantation. J Heart Lung Transplant 2001; 20: 304-309.

100 Leuschner G, Stocker F, Veit T, et al. Outcome of lung transplantation in idiopathic pulmonary fibrosis with previous anti-fibrotic therapy. J Heart Lung Transplant 2017; 37: P268-P274.

101 Mackintosh JA, Munsif M, Ranzenbacher L, et al. Risk of anastomotic dehiscence in patients with pulmonary fibrosis transplanted while receiving antifibrotics: experience of the Australian Lung Transplant Collaborative. J Heart Lung Transplant 2019; 38: 553-559.

102 Singer JP, Diamond JM, Anderson MR, et al. Frailty phenotypes and mortality after lung transplantation: a prospective cohort study. Am J Transplant 2018; 18: 1995-2004.

103 Singer JP, Diamond JM, Gries CJ, et al. Frailty phenotypes, disability, and outcomes in adult candidates for lung transplantation. Am J Respir Crit Care Med 2015; 192: 1325-1334.

104 Castleberry AW, Englum BR, Snyder LD, et al. The utility of preoperative six-minute-walk distance in lung transplantation. Am J Respir Crit Care Med 2015; 192: 843-852.

105 Weig T, Milger K, Langhans B, et al. Core muscle size predicts postoperative outcome in lung transplant candidates. Ann Thorac Surg 2016; 101: 1318-1325.

106 Rozenberg D, Mathur S, Wickerson L, et al. Frailty and clinical benefits with lung transplantation. J Heart Lung Transplant 2018; 37: 1245-1253.

107 Venado A, McCulloch C, Greenland JR, et al. Frailty trajectories in adult lung transplantation: a cohort study. J Heart Lung Transplant 2019; 38: 699-707.

108 Lee S, Paik HC, Haam SJ, et al. Sarcopenia of thoracic muscle mass is not a risk factor for survival in lung transplant recipients. J Thorac Dis 2016; 8: 2011-2017.

109 Li M, Mathur S, Chowdhury NA, et al. Pulmonary rehabilitation in lung transplant candidates. $J$ Heart Lung Transplant 2013; 32: 626-632.

110 Wickerson L, Rozenberg D, Janaudis-Ferreira T, et al. Physical rehabilitation for lung transplant candidates and recipients: an evidence-informed clinical approach. World J Transplant 2016; 6: 517-531.

111 Tobin RW, Pope CE 2nd, Pellegrini CA, et al. Increased prevalence of gastroesophageal reflux in patients with idiopathic pulmonary fibrosis. Am J Respir Crit Care Med 1998; 158: 1804-1808.

112 Schachter LM, Dixon J, Pierce RJ, et al. Severe gastroesophageal reflux is associated with reduced carbon monoxide diffusing capacity. Chest 2003; 123: 1932-1938.

113 Lee JS, Collard HR, Raghu G, et al. Does chronic microaspiration cause idiopathic pulmonary fibrosis? Am J Med 2010, 123: 304-311.

114 Richardson C, Agrawal R, Lee J, et al. Esophageal dilatation and interstitial lung disease in systemic sclerosis: a cross-sectional study. Semin Arthritis Rheum 2016; 46: 109-114. 
115 Lock G, Pfeifer M, Straub RH, et al. Association of esophageal dysfunction and pulmonary function impairment in systemic sclerosis. Am J Gastroenterol 1998; 93: 341-345.

116 Raghu G, Pellegrini CA, Yow E, et al. Laparoscopic anti-reflux surgery for the treatment of idiopathic pulmonary fibrosis (WRAP-IPF): a multicentre, randomised, controlled phase 2 trial. Lancet Respir Med 2018; 6: 707-714.

117 Lo WK, Burakoff R, Goldberg HJ, et al. Pre-transplant impedance measures of reflux are associated with early allograft injury after lung transplantation. J Heart Lung Transplant 2015; 34: 26-35.

118 Hartwig MG, Anderson DJ, Onaitis MW, et al. Fundoplication after lung transplantation prevents the allograft dysfunction associated with reflux. Ann Thorac Surg 2011; 92: 462-468.

119 King BJ, lyer H, Leidi AA, et al. Gastroesophageal reflux in bronchiolitis obliterans syndrome: a new perspective. J Heart Lung Transplant 2009; 28: 870-875.

120 Lo WK, Goldberg HJ, Wee J, et al. Both pre-transplant and early post-transplant antireflux surgery prevent development of early allograft injury after lung transplantation. J Gastrointest Surg 2016; 20: 111-118.

121 Biswas Roy S, Elnahas S, Serrone R, et al. Early fundoplication is associated with slower decline in lung function after lung transplantation in patients with gastroesophageal reflux disease. J Thorac Cardiovasc Surg 2018; 155: 2762-2771.

122 Collard HR, Ryerson CJ, Corte TJ, et al. Acute exacerbation of idiopathic pulmonary fibrosis. An international working group report. Am J Respir Crit Care Med 2016; 194: 265-275.

123 Dotan Y, Vaidy A, Shapiro WB, et al. Effect of acute exacerbation of idiopathic pulmonary fibrosis on lung transplantation outcome. Chest 2018; 154: 818-826.

124 Russo MJ, Iribarne A, Hong KN, et al. High lung allocation score is associated with increased morbidity and mortality following transplantation. Chest 2010; 137: 651-657.

125 van der Mark SC, Hoek RAS, Hellemons ME. Developments in lung transplantation over the past decade. Eur Respir Rev 2020; 29: 190132.

126 Román A, Calvo V, Ussetti P, et al. Urgent lung transplantation in Spain. Transplant Proc 2005; 37 3987-3990.

127 Hayanga AJ, Du AL, Joubert K, et al. Mechanical ventilation and extracorporeal membrane oxygenation as a bridging strategy to lung transplantation: significant gains in survival. Am J Transplant 2018; 18: 125-135.

128 Hayanga JWA, Hayanga HK, Holmes SD, et al. Mechanical ventilation and extracorporeal membrane oxygenation as a bridge to lung transplantation: closing the gap. J Heart Lung Transplant 2019; 38: 1104-1111.

129 Fuehner T, Kuehn C, Hadem J, et al. Extracorporeal membrane oxygenation in awake patients as bridge to lung transplantation. Am J Respir Crit Care Med 2012; 185: 763-768.

130 Lafarge M, Mordant P, Thabut G, et al. Experience of extracorporeal membrane oxygenation as a bridge to lung transplantation in France. J Heart Lung Transplant 2013; 32: 905-913.

131 Biscotti M, Gannon WD, Agerstrand C, et al. Awake extracorporeal membrane oxygenation as bridge to lung transplantation: a 9-year experience. Ann Thorac Surg 2017; 104: 412-419.

132 Anderson MR, Tabah A, RoyChoudhury A, et al. Procedure preference and intention-to-treat outcomes after listing for lung transplantation among U.S. adults. A cohort study. Ann Am Thorac Soc 2019; 16: 231-239.

133 Nathan SD, Shlobin OA, Ahmad S, et al. Comparison of wait times and mortality for idiopathic pulmonary fibrosis patients listed for single or bilateral lung transplantation. J Heart Lung Transplant 2010; 29: 1165-1171.

134 Chauhan D, Karanam AB, Merlo A, et al. Post-transplant survival in idiopathic pulmonary fibrosis patients concurrently listed for single and double lung transplantation. J Heart Lung Transplant 2016; 35: 657-660.

135 Nwakanma LU, Simpkins CE, Williams JA, et al. Impact of bilateral versus single lung transplantation on survival in recipients 60 years of age and older: analysis of United Network for Organ Sharing database. J Thorac Cardiovasc Surg 2007; 133: 541-547.

136 De Oliveira NC, Osaki S, Maloney J, et al. Lung transplant for interstitial lung disease: outcomes for single versus bilateral lung transplantation. Interact Cardiovasc Thorac Surg 2012; 14: 263-267.

137 Thabut G, Christie JD, Ravaud P, et al. Survival after bilateral versus single-lung transplantation for idiopathic pulmonary fibrosis. Ann Intern Med 2009; 151: 767-774.

138 Gerbase MW, Spiliopoulos A, Rochat T, et al. Health-related quality of life following single or bilateral lung transplantation: a 7-year comparison to functional outcome. Chest 2005; 128: 1371-1378.

139 Schaffer JM, Singh SK, Reitz BA, et al. Single- vs double-lung transplantation in patients with chronic obstructive pulmonary disease and idiopathic pulmonary fibrosis since the implementation of lung allocation based on medical need. JAMA 2015; 313: 936-948.

140 Villavicencio MA, Axtell AL, Osho A, et al. Single- versus double-lung transplantation in pulmonary fibrosis: impact of age and pulmonary hypertension. Ann Thorac Surg 2018; 106: 856-863.

141 Gulack BC, Ganapathi AM, Speicher PJ, et al. What is the optimal transplant for older patients with idiopathic pulmonary fibrosis? Ann Thorac Surg 2015; 100: 1826-1833. 
142 Black MC, Trivedi J, Schumer EM, et al. Double lung transplants have significantly improved survival compared with single lung transplants in high lung allocation score patients. Ann Thorac Surg 2014, 98: 1737-1741.

143 Yusen RD, Edwards LB, Dipchand Al, et al. The registry of the International Society for Heart and Lung Transplantation: thirty-third adult lung and heart-lung transplant report - 2016; focus theme: primary diagnostic indications for transplant. J Heart Lung Transplant 2016; 35: 1170-1184.

144 Clarson LE, Bajpai R, Whittle R, et al. Interstitial lung disease is a risk factor for ischaemic heart disease and myocardial infarction. Heart 2020; 106: 916-922.

145 Hubbard RB, Smith C, Le Jeune I, et al. The association between idiopathic pulmonary fibrosis and vascular disease: a population-based study. Am J Respir Crit Care Med 2008; 178: 1257-1261.

146 Mantel Ä, Holmqvist M, Jernberg T, et al. Rheumatoid arthritis is associated with a more severe presentation of acute coronary syndrome and worse short-term outcome. Eur Heart J 2015; 36: 3413-3422.

147 Asanuma Y, Oeser A, Shintani AK, et al. Premature coronary-artery atherosclerosis in systemic lupus erythematosus. N Engl J Med 2003; 349: 2407-2415.

148 Kizer JR, Zisman DA, Blumenthal NP, et al. Association between pulmonary fibrosis and coronary artery disease. Arch Intern Med 2004; 164: 551-556.

149 Khandhar SJ, Althouse AD, Mulukutla S, et al. Postoperative outcomes and management strategies for coronary artery disease in patients in need of a lung transplantation. Clin Transplant 2017, 31: e13026.

150 Meyer KC, Raghu G, Verleden GM, et al. An international ISHLT/ATS/ERS clinical practice guideline: diagnosis and management of bronchiolitis obliterans syndrome. Eur Respir J 2014; 44: 1479-1503.

151 Cantu E 3rd, Appel JZ 3rd, Hartwig MG, et al. J. Maxwell Chamberlain Memorial Paper. Early fundoplication prevents chronic allograft dysfunction in patients with gastroesophageal reflux disease. Ann Thorac Surg 2004; 78: 1142-1151.

152 Davidson JR, Franklin D, Kumar S, et al. Fundoplication to preserve allograft function after lung transplant: systematic review and meta-analysis. J Thorac Cardiovasc Surg 2020; 160: 858-866.

153 Davis RD Jr, Lau CL, Eubanks S, et al. Improved lung allograft function after fundoplication in patients with gastroesophageal reflux disease undergoing lung transplantation. J Thorac Cardiovasc Surg 2003; 125: 533-542.

154 Hirji SA, Gulack BC, Englum BR, et al. Lung transplantation delays gastric motility in patients without prior gastrointestinal surgery - a single-center experience of 412 consecutive patients. Clin Transplant 2017, 31: e13065.

155 Raviv Y, D’Ovidio F, Pierre A, et al. Prevalence of gastroparesis before and after lung transplantation and its association with lung allograft outcomes. Clin Transplant 2012; 26: 133-142.

156 Wahidi MM, Ravenel J, Palmer SM, et al. Progression of idiopathic pulmonary fibrosis in native lungs after single lung transplantation. Chest 2002; 121: 2072-2076.

157 King CS, Khandhar S, Burton N, et al. Native lung complications in single-lung transplant recipients and the role of pneumonectomy. J Heart Lung Transplant 2009; 28: 851-856.

158 Van Raemdonck D, Vos R, Yserbyt J, et al. Lung cancer: a rare indication for, but frequent complication after lung transplantation. J Thorac Dis 2016; 8: Suppl. 11, S915-S924.

159 Oldham JM, Collard HR. Comorbid conditions in idiopathic pulmonary fibrosis: recognition and management. Front Med 2017; 4: 123.

160 Triplette M, Crothers K, Mahale P, et al. Risk of lung cancer in lung transplant recipients in the United States. Am J Transplant 2019; 19: 1478-1490.

161 Olland AB, Falcoz PE, Santelmo N, et al. Primary lung cancer in lung transplant recipients. Ann Thorac Surg 2014; 98: 362-371.

162 Banga A, Sahoo D, Lane CR, et al. Disease recurrence and acute cellular rejection episodes during the first year after lung transplantation among patients with sarcoidosis. Transplantation 2015; 99: 1940-1945.

163 King MB, Jessurun J, Hertz MI. Recurrence of desquamative interstitial pneumonia after lung transplantation. Am J Respir Crit Care Med 1997; 156: 2003-2005.

164 Scallan C, Venado A, Han L, et al. Recurrent pulmonary fibrosis in a lung allograft secondary to de novo antisynthetase syndrome. Ann Am Thorac Soc 2020; 17: 901-904. 